\title{
FÓRUNS ONLINE NA FORMAÇÃO CRÍTICO-REFLEXIVA DE PROFESSORES DE LÍNGUAS ESTRANGEIRAS: UMA REPRESENTAÇÃO DO PENSAMENTO CRÍTICO EM FASES NA/PELA LINGUAGEM
}

\section{Cibele Cecilio de Faria ROZENFELD*}

- RESUMO: Este trabalho tem como objetivo apresentar o recorte de uma investigação que focalizou a formação inicial de professores de língua estrangeira (alemão e inglês) e lançou luzes sobre os estágios obrigatórios do quarto ano, considerando a possibilidade que fóruns online de um ambiente virtual podem oferecer para a manifestação do pensamento crítico dos futuros professores. Analisamos os temas abordados e as mensagens de três fóruns, com base no conceito de pensamento crítico e no modelo teórico de Investigação Prática de Garrison, Anderson e Archer $(2000,2001)$. Para uma melhor compreensão das fases nas discussões dos tópicos, utilizamos o modelo dos autores, identificando também alguns marcadores discursivos característicos de cada uma delas, com base nos pressupostos da Linguística SistêmicoFuncional (HALLIDAY, 1994) e nos tipos de movimentos conversacionais (moves) propostos por Eggins e Slade (1997). A partir dos subsídios teóricos selecionados e da análise dos dados, foi possível desenvolver um novo modelo e concluir que o fórum online pode ser considerado uma importante ferramenta para a manifestação do pensamento crítico de professores e para uma formação crítico-reflexiva, em um contexto marcado por especificidades da sociedade de informação.

- PALAVRAS-CHAVE: Fóruns online. Pensamento crítico. Estágio supervisionado de língua estrangeira. Formação inicial de professores de línguas.

\section{Introdução}

As transformações que vêm ocorrendo na sociedade contemporânea em diferentes setores são hoje incontestáveis. Em decorrência disso, verifica-se a existência de consonância entre estudiosos do campo educacional e da Linguística Aplicada, de que é necessário que ocorram mudanças na formação inicial de professores, a fim de que esta possa estar alinhada com os novos desafios impostos pela sociedade atual.

Ao fazer parte do processo de formação inicial de professores de língua estrangeira como docente, assumindo as disciplinas "Estágio Supervisionado

* UNESP - Universidade Estadual Paulista. Faculdade de Ciências e Letras - Departamento de Letras Modernas. Araraquara - SP - Brasil. 14800-901 - cibeleroz@yahoo.com.br 
de Prática de Ensino de Língua Estrangeira (inglês e alemão)",, 1 deparei-me com algumas dificuldades e necessidades inerentes, em especial, ao contexto específico da disciplina. Apesar de serem previstos encontros semanais e regulares ao longo do semestre com os licenciandos da disciplina, que tinham (e ainda têm) como objetivo central a apresentação e discussão de conteúdos teóricos sobre aspectos do processo de ensino e aprendizagem de língua estrangeira (LE) e a articulação entre teoria e prática; de fato, o número elevado de licenciandos em sala não permitia um aprofundamento na reflexão crítica das práticas vivenciadas nos estágios por cada um deles.

Diante desse quadro, senti um grande abismo entre mim, docente responsável e supervisora dos estágios, e os licenciandos, e uma grande necessidade de maior proximidade entre nós para a troca de experiência, de informação, para esclarecimentos, bem como de um espaço para a reflexão sobre as práticas vivenciadas.

O foco da pesquisa desenvolvida voltou-se, assim, para a formação inicial e o potencial de um ambiente virtual como espaço capaz de possibilitar a aproximação docente-licenciandos e licenciando-licenciando, e como forma de promover melhor acompanhamento das atividades realizadas por eles em suas primeiras experiências com as ações docentes e de favorecer a reflexão e o desenvolvimento do pensamento crítico.

Partimos da premissa de que o ambiente virtual poderia viabilizar maior interação entre alunos para discussão das situações de estágio, contribuindo para a construção do conhecimento e favorecendo o desenvolvimento do pensamento crítico. O foco da investigação centrou-se, assim, na compreensão do processo reflexivo no meio virtual, mais especificamente em fóruns online, como ferramenta com potencialidades para o desenvolvimento do pensamento crítico, e nossa busca teórica foi direcionada para esse objetivo.

Este trabalho tem como objetivo, portanto, apresentar os resultados dessa investigação realizada. ${ }^{2}$

\section{As bases teóricas da pesquisa}

Os eixos teóricos que deram sustentação à pesquisa foram prioritariamente: 0 campo de estudos sobre formação de professores, a noção de pensamento crítico

\footnotetext{
Durante parte do período de desenvolvimento da investigação apresentada neste trabalho, a autora atuou como responsável pela disciplina Estágio Supervisionado de Prática de Ensino de Língua Estrangeira (inglês e alemão), na Universidade Estadual Paulista, campus Araraquara, curso de Letras, na função de bolsista didática.

2 Confira Rozenfeld (2011).
} 
e de Comunidade de Investigação (GARRISON; ANDERSON; ARCHER, 2001), a Linguística Sistêmico-Funcional (LSF) (HALLIDAY, 1994) e as funções do discurso (moves) (EGGINS; SLADE, 1997).

No primeiro eixo teórico, discutimos o paradigma reflexivo de formação de professores, que tem origem nos estudos de Dewey (1959a, 1959b), foi expandido por Schön $(1983,1987)$ e descrito também por Zeichner e Liston (1996), Perrenoud (2002), Nóvoa (1992), bem como Freire (1979) e Pimenta (2002) no Brasil, e diversos outros. Zeichner e Liston (1996) afirmam que, histórica e conceitualmente, Dewey forneceu o fundamento para nossa compreensão de ensino reflexivo.

Dewey (1959a, 1959b) valorizou a experiência como elemento fundamental para a constituição do sujeito. Baseado nos trabalhos do autor, Schön $(1983,1987)$ dá continuidade ao desenvolvimento do conceito e postula que as instituições educacionais deveriam repensar a epistemologia da prática e os pressupostos pedagógicos, segundo os quais seus currículos estão baseados. O autor advoga a prática reflexiva como elemento-chave para a educação profissional. Ele define essa prática como aquela que poderá ajudar profissionais a adquirir os tipos de arte essenciais para as competências em zonas indeterminadas de prática, ${ }^{3}$ referindo-se ao termo "arte profissional" (Professional artistry) como conjunto de competência que os profissionais possuem em situações únicas, incertas e conflituosas da prática.

No campo do ensino de línguas, Moita Lopes (1996) ressalta a relevância de uma formação teórico-crítica, a fim de problematizar aquela visão dogmática, segundo a qual os professores de línguas são simplesmente treinados a usar técnicas acabadas de ensino a serem aplicadas em sala de aula em qualquer contexto. O autor reafirma que, para que o professor deixe de ser um mero executor de métodos desenvolvidos por outros pesquisadores, que se encontram fora de sua sala de aula, é necessário que em sua formação ele se envolva na reflexão crítica sobre seu próprio trabalho.

Vieira-Abrahão (2007) aponta para o fato de que para uma atuação do professor no paradigma reflexivo é necessário que existam instrumentos para se utilizar com o intuito de aprimoramento de suas práticas, buscando estimular e iniciar o aluno em práticas reflexivas. É importante que se encontrem formas para o desenvolvimento da autonomia do professor, com o intuito de possibilitar a busca de caminhos dentro de sala de aula em diferentes contextos.

Compartilhamos a visão da autora e acreditamos que as universidades não podem dar as costas aos estudos teóricos do campo de formação de professores

3 No original: "[... ] a practicum aimed at helping students acquire the kinds of artistry essential to competence in the indeterminate zones of practice". (SCHÖN, 1987, p.18). 
e devem sempre buscar nortear suas práticas para a formação crítico-reflexiva do futuro docente.

Nesse sentido, a ideia de criação de um ambiente virtual, denominado "Reflections...Überlegungen...Dúvidas", em referência às três línguas envolvidas na disciplina, surgiu como alternativa para o desenvolvimento do pensamento crítico e reflexivo durante as práticas de sala de aula, tanto nos estágios obrigatórios de observação quanto de regência, conforme mencionado. Buscou-se elaborar um ambiente com características de um "local de encontros", destinado a reflexões, discussões, esclarecimentos, questionamentos, trocas de experiências. Diante das diferentes disponibilidades de horários de licenciandos e do professor, o uso do ambiente nos pareceu oferecer grande vantagem, pois os encontros aconteciam assincronamente, ou seja, em tempos distintos. Dessa forma, tornouse mais praticável o incentivo ao processo reflexivo dos futuros professores e o acompanhamento individual de cada um deles pelo professor e pelos colegas. Além disso, o uso de um ambiente virtual vem ao encontro daquilo que está previsto nas diretrizes da Resolução n ${ }^{\circ} \mathrm{CNE} / \mathrm{CP} 1$, de 18 de fevereiro de 2002, Artigo 13, §2 (CONSELHO NACIONAL DE EDUCAÇÃO, 2002), ${ }^{4}$ no que concerne à importância de inclusão de novas tecnologias em processos de formação de professores.

Para a análise das mensagens nos fóruns, tomamos o modelo de Investigação Crítica de Garrison, Anderson e Archer (2001) e Garrison e Anderson (2003), utilizando ainda subsídios da Linguística Sistêmico-Funcional de Halliday (1994) e os movimentos conversacionais (moves) de Eggins e Slade (1997) como referências, considerando a interação e a comunicação no interior de cada tópico e a manifestação do pensamento crítico.

Garrison, Anderson e Archer (2001) identificaram a "presença cognitiva", a "presença social" e a "presença de ensino" como os elementos constitutivos de uma comunidade de investigação para fins educacionais. De acordo com os autores, tais elementos são necessários para estimular ou inibir a qualidade da experiência educacional e do produto da aprendizagem, sendo a presença cognitiva diretamente relacionada com o desenvolvimento de pensamento crítico.

A presença cognitiva é, conforme os autores, o elemento mais fundamental do modelo para o sucesso da experiência educacional. O termo "presença cognitiva" é tomado por eles em referência à capacidade dos participantes de uma comunidade de investigação de construir sentidos por meio de uma comunicação sustentada. Esse elemento é essencial para o desenvolvimento do pensamento crítico, como processo e como produto, tomado comumente como objetivo de ensino superior.

\footnotetext{
De acordo com a Resolução referida: "A presença da prática profissional na formação do professor, que não prescinde da observação e ação direta, poderá ser enriquecida com tecnologias da informação, incluídos o computador e o vídeo, narrativas orais e escritas de professores, produções de alunos, situações simuladoras e estudo de casos." (BRASIL, 2002).
} 
Os autores entendem ainda que a integração do mundo público e privado dos aprendizes é o cerne para a criação de presença cognitiva.

O modelo de Investigação Crítica define quatro fases essenciais para descrever e compreender a presença cognitiva em processos educacionais e que correspondem ao processo de pensamento crítico (representação na Figura 1).

Figura 1 - Modelo de Investigação Crítica

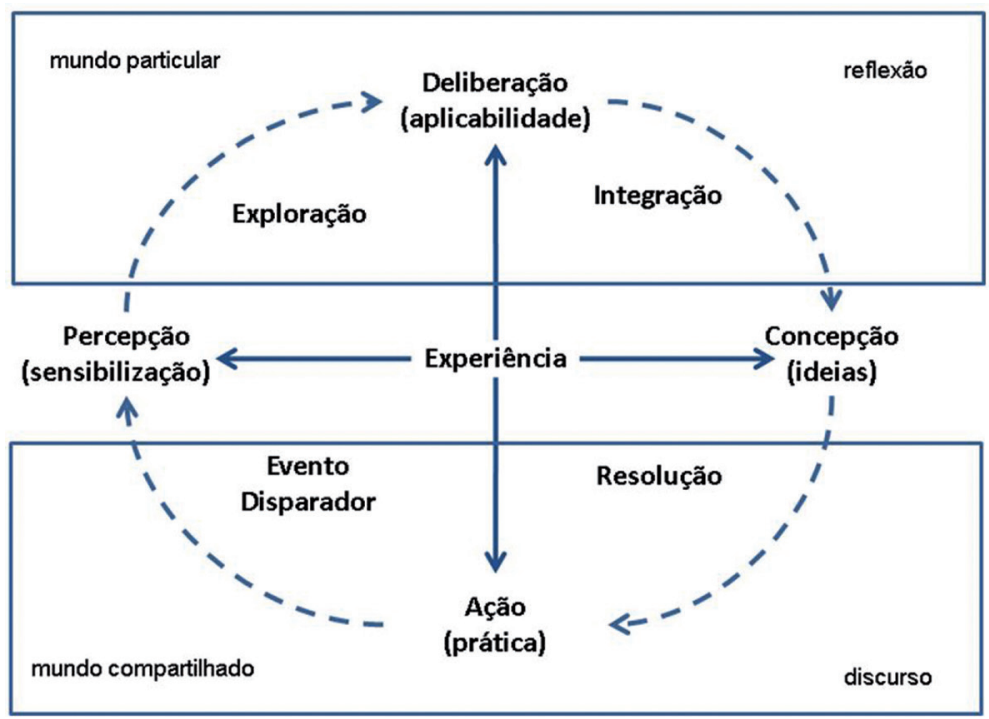

Fonte: Baseado em Garrison, Anderson e Archer (2001) e em Garrison e Anderson (2003, p.59).

- Primeira fase: reflete a fase inicial de prática de investigação e é marcada por um Evento Disparador (triggering event). De acordo com Garrison e colaboradores, aqui é reconhecido um problema, um tema, um dilema, que emerge da experiência. Em um contexto educacional, frequentemente o professor explicita desafios de aprendizagem ou uma atividade e estes poderão se tornar o evento disparador. No entanto, no contexto de comunicação mediada por computador (CMC) qualquer membro do grupo de participantes pode adicionar um evento disparador ao discurso, de forma proposital ou indireta.

- Segunda fase: nesta fase, denominada de Exploração (exploration), os participantes se deslocam entre o mundo particular, reflexivo e o mundo social de exploração de ideias. No início dessa fase, os alunos são estimulados a perceber a natureza de um problema e a buscar a exploração de informações relevantes sobre ele. Esta fase é caracterizada por um brainstormming, por questionamentos e troca de informação. Nesse momento eles são estimulados a refletir e a compartilhar ideias colaborativamente. 
- Terceira fase: chamada de fase de Integração (integration), essa fase é caracterizada pela construção de significado para as ideias geradas na fase exploratória. Na transição da fase exploratória, os alunos passarão a refletir sobre a aplicabilidade das ideias. Mais uma vez, os aprendizes estarão em movimento entre reflexão e discurso e buscarão tomar decisões para integrar as ideias.

- Quarta fase: a última fase é chamada Resolução (resolution) de um dilema ou problema por ação direta ou indireta. Configura-se pela confirmação de solução, teste ou aplicação direta. Em contextos não educacionais essa fase significa a implantação de uma solução proposta ou um teste de hipótese. No campo educacional, o final dessa fase pode significar voltar-se para um novo problema, assumindo-se que os alunos adquiriram conhecimento relevante.

Para o reconhecimento das mensagens em fases (no caso das várias mensagens inseridas em um tópico do fórum), os autores propõem tabelas com indicadores e descritores para cada uma delas. No entanto, durante a análise dos dados, notamos que tais indicadores possuem limitações, tendo em vista que eles se baseiam mais em conteúdos e não oferecem elementos precisos de descrição. A fim de realizar uma análise mais minuciosa das mensagens, buscamos especificar os descritores a partir da identificação de elementos linguísticos nos descritores, os quais foram obtidos com respaldo em estudos da Linguística Sistêmico-Funcional (HALLIDAY, 1994), e seus conceitos de Metafunção Ideacional, Interpessoal, e nos movimentos conversacionais (moves) de Eggins e Slade (1997). Assim, expandimos o modelo de Garrison e colaboradores, incluindo alguns elementos discursivos dessas correntes teóricas aos indicadores das diferentes fases. ${ }^{5}$

A razão por termos optado pela LSF como aparato teórico de suporte à pesquisa foi o fato de ela ser uma corrente que não se fundamenta unicamente em elementos formais, estruturais, mas de um lado em funções, de outro em sentidos, tidos como escolhas, pelas quais uma língua, bem como qualquer outro sistema semiótico, é interpretada.

A questão central na gramática funcional de Halliday é a maneira como os significados são expressos, colocando as formas de uma língua "[...] como meios para um fim, não como um fim em si mesma." (NEVES, 2002, p.73). Para a análise dos dados da presente pesquisa, utilizamos as noções de metafunção ideacional e interpessoal.

A metafunção ideacional está relacionada com o sentido da oração como representação, como função experiencial, seu aspecto como um caminho para representar modelos de experiência. Compreende-se a língua como aquela que capacita o ser humano a formar um quadro da realidade, a construir sentidos sobre

5 Confira Rozenfeld (2011). 
as coisas que se passam ao seu redor e em seu interior (HALLIDAY, 1994). Nesse sentido, a oração ocupa um papel central, porque concretiza um princípio geral de modelação de experiência: o princípio de que a realidade é feita de processos.

A metafunção ideacional está centrada no conteúdo do discurso, nas atividades que se realiza e em quem e como são os participantes dessas atividades e identifica quatro tipos de processos principais: o de fazer, sentir, dizer e ser. Ela representa um procedimento de reflexão, de organização do fluxo de eventos; e o sistema gramatical, que torna isso possível, é denominado processo de "transitividade".

O processo de transitividade nos permite responder às questões: Que tipo de processo é esse? Quais os participantes envolvidos? Em que circunstâncias ocorre o processo de comunicação? O sistema de transitividade reconstrói o mundo das experiências em dois tipos de processos: as experiências do mundo exterior constituem o processo material, e as do mundo interior, o processo mental. As experiências exteriores são constituídas de ações ou eventos, de pessoas ou de outros atores que realizam coisas. Já a experiência interior é uma reação ao processo das vivências exteriores, que são gravadas e que refletem sobre ela: ela é uma conscientização de nosso estado e forma de ser.

Existem ainda outros tipos de processos envolvidos na metafunção ideacional, representados na Tabela 1, que sintetizam os tipos de processos, seus significados e participantes.

Tabela 1 - Metafunção ideacional e tipos de processos

\begin{tabular}{|c|c|c|}
\hline TIPO DE PROCESSO & $\begin{array}{l}\text { SIGNIFICADO } \\
\text { PRINCIPAL }\end{array}$ & PARTICIPANTES \\
\hline $\begin{array}{l}\text { MATERIAL } \\
\text { ação, evento }\end{array}$ & fazer, acontecer & ator........meta \\
\hline $\begin{array}{l}\text { MENTAL } \\
\text { de percepção, } \\
\text { de cognição } \\
\text { de afetividade }\end{array}$ & $\begin{array}{l}\text { ver, ouvir } \\
\text { (percepção) } \\
\text { gostar, temer } \\
\text { (afetividade) } \\
\text { pensar, saber, } \\
\text { compreender } \\
\text { (cognição) }\end{array}$ & $\begin{array}{l}\text { experienciador..... } \\
\text { fenômeno, fato }\end{array}$ \\
\hline $\begin{array}{l}\text { RELACIONAL } \\
\text { de atribuição, } \\
\text { de identificação }\end{array}$ & $\begin{array}{l}\text { ser, } \\
\text { atribuir, } \\
\text { identificar }\end{array}$ & $\begin{array}{l}\text { portador, atributo } \\
\text { identificado, } \\
\text { identificador }\end{array}$ \\
\hline
\end{tabular}




\section{TIPO DE PROCESSO SIGNIFICADO} PRINCIPAL

\begin{tabular}{lll}
\hline $\begin{array}{l}\text { VERBAL } \\
\text { de linguagem }\end{array}$ & $\begin{array}{l}\text { dizer } \\
\text { significar }\end{array}$ & $\begin{array}{l}\text { dizente, recebedor } \\
\text { palavreado e alvo }\end{array}$ \\
\hline $\begin{array}{l}\text { COMPORTAMENTAL } \\
\text { de ação a partir de } \\
\text { conscientização }\end{array}$ & atuar & comportante \\
\hline $\begin{array}{l}\text { EXISTENCIAL } \\
\text { de ser }\end{array}$ & $\begin{array}{l}\text { existir, ser, } \\
\text { acontecer }\end{array}$ & existente \\
\hline
\end{tabular}

Fonte: Baseado em Thompson (2004, p.143) e Gervai (2007).

No âmbito da metafunção interpessoal destacamos a importância de perceber os propósitos, as atitudes e as intenções do falante no momento da interação, os quais serão determinados pelas escolhas léxico-gramaticais e pelos mecanismos linguísticos que ele dispõe no momento em que desempenha e projeta papéis. Tais escolhas estarão sempre relacionadas a seus interesses e ao que quer alcançar (GERVAI, 2007).

Os eixos "dar/pedir bens e serviços "e "dar/pedir informações " formam juntos o que Halliday define como "sistema de modalidade", que irá enquadrar sinais de opinião do falante/escritor do texto. Essas funções da linguagem estão imbuídas na oração e são descritas na LSF por meio do Modo (mood), da Modalidade (modality), Valoração (appraisal) e Negociação (negotiation) (THOMPSON, 2004).

A metafunção interpessoal é definida como o sistema que estabelece os papéis da fala. Esses papéis são as identidades que as pessoas tomam para si no momento das interações, ao serem assumidos, e estabelecem uma relação entre os participantes. Sempre que usamos a língua, nós a usamos para a troca, para a interação e nossa primeira escolha deve ser a de decidir se assumiremos o papel de iniciador ou de receptor. Esses papéis se resumem basicamente em oferecer ou pedir algo.

Assim, os tipos mais fundamentais de papéis no discurso são: dar (giving) e pedir (demanding). Ambos têm como objetivo expressar significados interpessoais. O emissor, além de estar no papel de fazer algo para si mesmo, também está solicitando algo do receptor. Dessa forma, um ato de fala é algo que pode ser chamado de "interato", visto que aquele que fala não faz nada sozinho: é uma troca, na qual "dar" implica "receber" e "pedir" implica "dar" em resposta (HALLIDAY, 1994).

A metafunção interpessoal e o sistema de modalidade são sintetizados da forma representada nas Figuras 2 e 3. 
Figura 2 - Metafunção Interpessoal e Sistema de Modalidade (a)

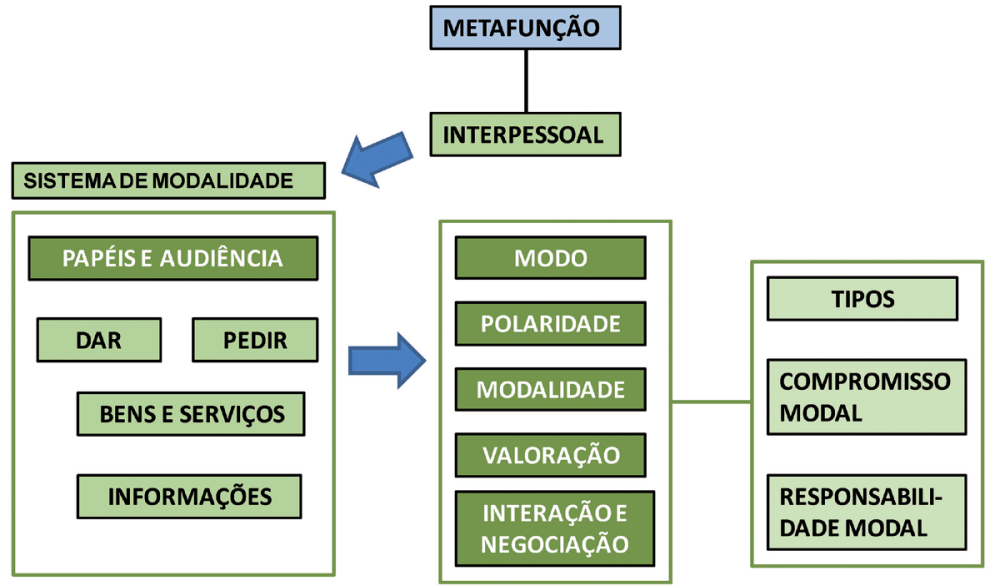

Fonte: Rozenfeld (2011, p.108).

Figura 3 - Metafunção Interpessoal e Sistema de Modalidade (b)

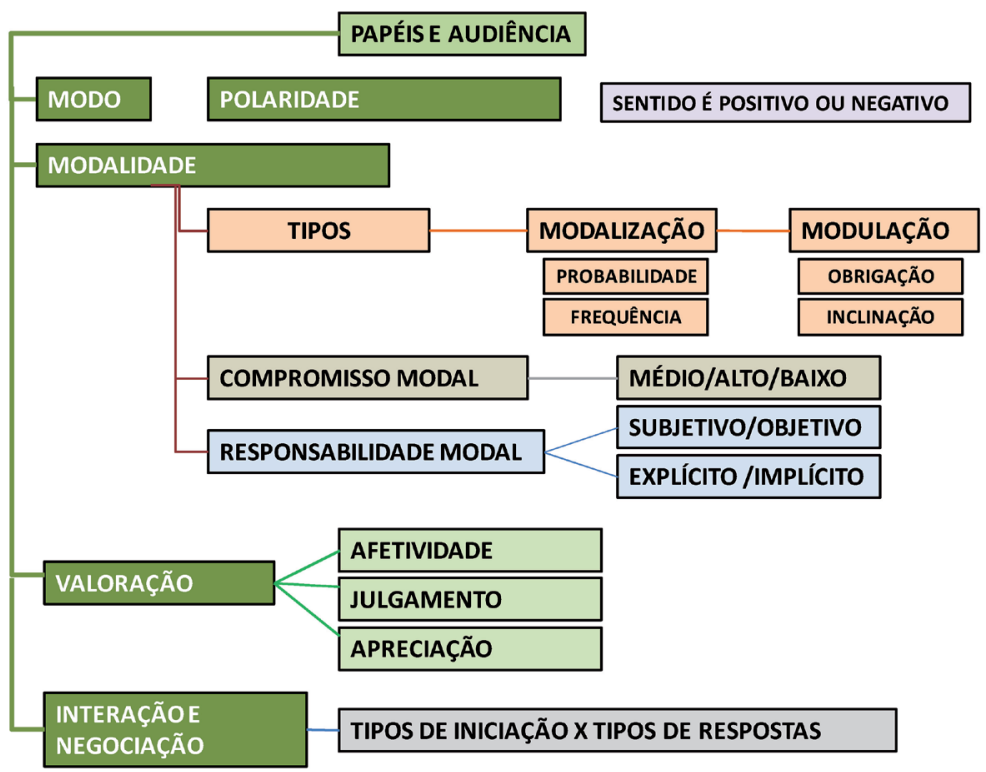

Fonte: Rozenfeld (2011, p.108).

Além da LSF de Halliday, consideramos para a análise das mensagens os movimentos conversacionais postulados por Eggins e Slade (1997). 
Partindo dos pressupostos da LSF, em especial, do modelo de Halliday, as autoras observaram que para analisar a interatividade é necessário que gramática e semântica sejam consideradas pela perspectiva dos tipos de movimentos conversacionais (moves), que são denominados pelas autoras como funções do discurso (speech functions), e que é necessário olhar para um diálogo por duas perspectivas distintas: pela da gramática, que constitui a estrutura de modo, e pela do discurso, que se relaciona aos tipos de movimentos realizados no contexto interativo. A primeira nos dá informações sobre os papéis sociais e a segunda sobre como os participantes estão constantemente negociando sentidos e relações de solidariedade e intimidade. As duas formas juntas contribuem para a compreensão de como os participantes concretizam suas diferenças interpessoais em uma conversa informal e, assim, de como o poder é negociado através das falas correntes (EGGINS; SLADE, 1997).

Para representar os modelos de funções do discurso, Eggins e Slade (1997) apresentam um sistema de rede, no qual existem categorias mais centrais, inclusivas e suas subclassificações, indicando maior detalhamento na descrição. Os critérios para estabelecer as categorias das funções do discurso são linguísticos: cada classe de função pode ser estabelecida funcionalmente, gramaticalmente (modo e modalidade) e semanticamente (em termos de escolhas de valoração e envolvimento). Apresentamos na Tabela 2 alguns exemplos de movimentos conversacionais.

Tabela 2 - Recorte do modelo dos movimentos conversacionais de Eggins e Slade (1997)

\begin{tabular}{llll}
\hline \multirow{2}{*}{$\begin{array}{l}\text { Movimentos } \\
\text { conversacionais } \\
\text { (moves) }\end{array}$} & Abrir & Preparar-se para a interação & ........etc. \\
\cline { 2 - 3 } & & Iniciar & $\ldots \ldots . .$. etc. \\
\hline
\end{tabular}

Fonte: Baseado em Eggins e Slade (1997).

\section{As fases da manifestação do pensamento crítico nos fóruns e os dados da pesquisa}

A constituição do corpus foi feita a partir da seleção de três fóruns do ambiente virtual "Reflections...Überlegungen...e Dúvidas", que tinham como objetivo discutir situações de sala de aula observadas durante o estágio de observação ou vivenciadas durante a regência dos licenciandos. Os fóruns tinham como título: 1) Temas relevantes para discussão (fórum aberto previamente ao início dos 
estágios); 2) Fórum de reflexões: estágio de observação e 3) Fórum de reflexões: estágio de regência.

Para analisar as discussões (número total: 72; mensagens: 427), realizamos 6 leituras das mensagens de cada tópico (1a e 1b, 2a e 2b, 3a e 3b). Na análise 1a e 1b utilizamos como referência de análise exclusivamente o modelo de Investigação Crítica e os indicadores/descritores apresentados por Garrison e colaboradores em quatro diferentes tabelas, sendo uma para cada fase. Notamos que o grau de coerência no enquadramento das mensagens em fases nas duas leituras foi bastante baixo, por isso expandimos as tabelas de indicadores, associando a eles alguns marcadores linguísticos, que pudessem levar a um melhor reconhecimento das fases. Munidos de novas tabelas, realizamos as leituras 2a e 2b. Apesar de ter havido maior coerência nas duas novas leituras, ainda notamos que a característica linear e fechada do modelo de Investigação Crítica impunha limitações e, por essa razão, com base nos subsídios teóricos descritos anteriormente, desenvolvemos um modelo de representação da manifestação do pensamento crítico em fóruns (Figura 4) como referência para nossa análise e, a partir do novo modelo e seus indicadores, realizamos as leituras $3 \mathrm{a}$ e 3b.

Figura 4 - Modelo de representação da manifestação do pensamento crítico em fóruns

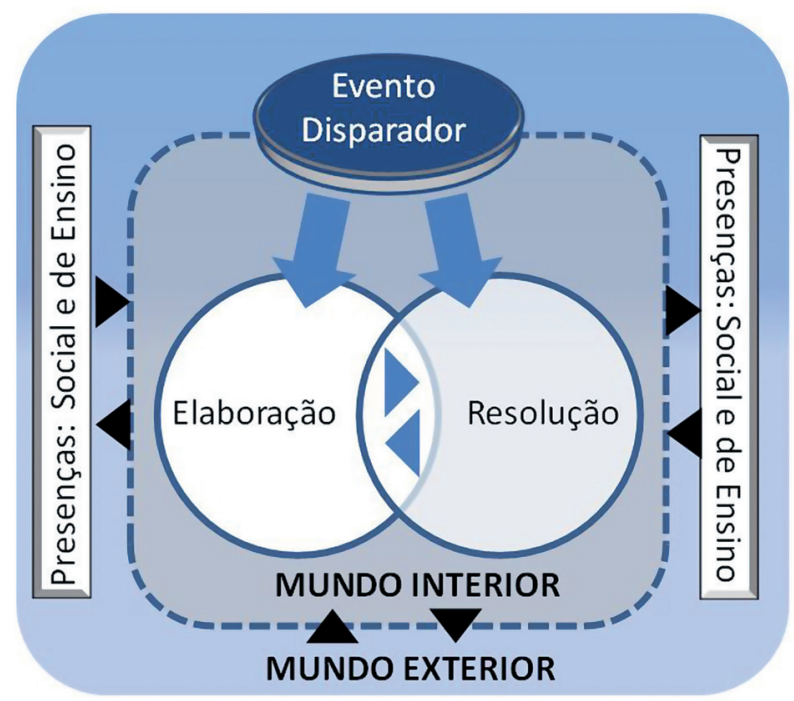

Fonte: Rozenfeld (2011, p.171). 
Em nosso entendimento, o processo de desenvolvimento do pensamento crítico em/sobre questões educacionais, em específico ensino e aprendizagem de LE, envolve variáveis, que vão desde as individuais dos participantes até as institucionais, culturais, políticas. Por tratar-se de fenômeno repleto de incertezas e imprevisibilidades, requer um modelo de análise que apresente uma maior flexibilidade em sua representação. Tendo o pensamento crítico sua origem em contextos tão diversificados, verificou-se não ser possível a sua representação em um modelo linear, com fases rigidamente pré-estabelecidas. Ao contrário, sua representação deve prever movimentações, inversões, modificações. Nessa perspectiva, e tomando como referência teórica o modelo de Investigação Crítica de Garrison e colaboradores, as metafunções ideacional e interpessoal da LSF de Halliday e os movimentos conversacionais de Eggins e Slade, elaboramos o modelo apresentado na Figura 4, bem como definimos os indicadores de cada fase, para depois realizarmos duas novas leituras (3a e 3b).

Consideramos em nossa proposta o fato de que a comunicação escrita assíncrona ocorre de forma diferente da síncrona: as tomadas de turnos pelos participantes ocorrem em tempos distintos, dificultando o reconhecimento de um sequenciamento, que se percebe mais condicionado às características do espaço criado no universo da escrita virtual do que ao tempo. O processo de leitura e interpretação torna-se muito importante nesse tipo de comunicação.

Buscamos representar no modelo o fato de que, em todas as fases, os participantes irão experienciar a alternância entre o mundo interno (reflexivo, particular) e o externo (compartilhado, social), uma vez que as ideias são exploradas colaborativamente e os estudantes vão construindo sentidos individualmente e na interação com o grupo para as proposições, as quais também são resultado da inter-relação entre o mundo externo e interno. Valendo-se dessa reflexão, representamos a interface entre os dois mundos no modelo por uma superfície permeável, pois permite trocas durante todo o processo.

Vale destacar ainda o lugar da presença social e de ensino no modelo. Apesar de tais presenças não terem sido foco de investigação, foi possível verificar que elas influenciam diretamente o processo e essa influência não se restringe a uma única fase, mas perpassa todas elas, podendo alterar fortemente o desdobramento e desenvolvimento do pensamento crítico. Por essa razão, definimos seu posicionamento à esquerda e à direita do modelo de fases, visto que elas refletem e refratam o processo nelas desenvolvidos.

Consideramos o modelo proposto mais adequado para representar as características do processo de desenvolvimento do pensamento crítico em comunidade de investigação em fóruns, e advogamos sua continuação em três momentos principais: evento disparador, elaboração e resolução. Parte-se sempre do evento disparador, mas segue-se para uma fase de resolução ou de elaboração ou para a intersecção das duas. 
Discorreremos mais minuciosamente a seguir sobre cada uma das fases da proposta, seus indicadores, ao mesmo tempo em que apresentaremos alguns dos dados coletados. Destacamos que houve, nas duas análises realizadas com referência no modelo (3a e 3b), um alto grau de coerência no enquadramento das mensagens.

\section{Fase evento disparador}

Ao início do trabalho nos tópicos, uma discussão, destinada à reflexão, sempre parte do reconhecimento de um tema relevante de acordo com a interpretação de quem a inicia, constituindo, assim, uma fase de evento disparador. O evento disparador (ED) pode incluir uma questão explícita, uma descrição de uma situação intrigante, a apresentação de uma informação pertinente ou um relato, capazes de desencadear uma discussão sobre um tema. Além disso, ele pode também conter uma questão implícita, podendo nesse caso expressar uma dúvida, uma incerteza, um pedido de opinião.

Nesse sentido, corroboramos o modelo proposto por Garrison e colaboradores (GARRISON; ANDERSON; ARCHER, 2000, 2001; GARRISON; ARCHER, 2000; GARRISON; ANDERSON, 2003); no entanto, acrescentamos que o evento disparador pode ser uma reflexão em fase de resolução pessoal, ou seja, marcada por uma certeza e por compartilhamento de ideias, por orações afirmativas, que irão se constituir como compartilhamento de ideias e como tema para reflexão do grupo.

Apresentamos na Tabela 3 a quantificação de mensagens da fase evento disparador com as três diferentes características.

Tabela 3 - Mensagens evento disparador: tipo/número

\begin{tabular}{ll}
\hline $\begin{array}{l}\text { EDs que incluem tema } \\
\text { para reflexão na forma de: }\end{array}$ & № de mensagens \\
\hline Orações afirmativas & 14 \\
\hline Questão implícita & 4 \\
\hline Questão explícita & 54 \\
\hline
\end{tabular}

Fonte: Rozenfeld (2011).

Podemos observar nos dados da tabela a predominância de mensagens da fase evento disparador com explicitação de questão no corpo do texto. Notamos que, em sua maioria, elas são elaboradas com um texto de contextualização (uma descrição, um relato sobre uma situação de sala de aula vivenciada pelo 
autor ou um insight) e uma questão proposta ao grupo posicionada anterior ou posteriormente a ele. Apresentamos a seguir exemplos de tais mensagens (com grifos nossos):

\begin{abstract}
Relato de situação anterior + questão explícita:
PAULA $^{6}$ (25/03) (Tema: Gramática Indutiva). Em uma das aulas que eu assisti a professora fez o seguinte: primeiramente, ela distribuiu tiras de papel que continham uma pergunta que envolvia algum tipo de futuro (will, going to ou fututo com present continuous). Os alunos tinham que discutir entre eles aquelas perguntas, dar o feedback da discussão e, em seguida, levantar e "colar" as tiras em colunas que estavam nas paredes e divididas da seguinte forma: 1) a coluna "futuro-will" tinha o nome de PREDICTION/PROMISES/OFFERS; 2) "futuro-going to" tinha o nome de PLANS/INTENTIONS; 3) "futuro present continuous" tinha o nome de ARRANGEMENTS. Só depois disso é que ela começou a explicar os futuros e seus contrastes, sempre pedindo para que eles formulassem as regras e os usos. O que vocês acham dessa atividade? É uma maneira válida e produtiva de ensinar gramática? ${ }^{7}$
\end{abstract}

\title{
Questão explícita + reflexão posterior sobre uma situação:
}

PAULA (20/03): (Tema:Aprimorando instruções). Como dar instruções aos alunos de forma clara e objetiva sobre como fazer um exercício em sala de aula? Ainda tenho essa dificuldade qdo estou dando aula !! Tenho que repetir pelo menos uma vez o procedimento !! Achei que seria algo simples e fácil, mas descobri que ter clareza na instrução é uma tarefa mto complicada!

\section{Reflexão ou relato sem questão:}

ANGELA (18/03): (Tema: o ensino de LE na escola pública). Na minha opinião, devemos refletir sobre o ensino de LE na escola pública, já que um dos objetivos da universidade pública é formar profissionais que atuem nesse contexto.

\section{Questão implícita:}

VINICIUS (18/03): (Tema: ensino de gramática de LE) Este tema me interessa porque não sei como combinar exercícios de produção e recepção de textos orais e escritos com o ensino de gramática "pura".

A questão implícita na mensagem de Vinicius poderia ser, por exemplo: "como combinar exercícios de produção e recepção de textos orais e escritos com o ensino de gramática 'pura'?".

Os nomes dados aos participantes da pesquisa são fictícios, criados especificamente para a pesquisa, com o intuito de preservação de identidade.

7 Os excertos são apresentados neste trabalho tal qual produzidos pelos alunos, ainda que eles apresentem problemas de adequação linguística, acentuação ou digitação. 
Também observamos uma questão implícita em:

RENITA (14/05): (Tema: Situações desagradáveis). Olá pessoal, tudo bem? Gostaria que vocês opinassem na seguinte situação que aconteceu no meu estágio: A classe estava uma bagunça, e a professora estava tentanto explicar o exercício a ser feito. Repentinamente um par de tênis foi lançado contra a parede. Vocês acreditam???

Na mensagem de Renita, a questão que se encontra implícita não é aquela marcada explicitamente no texto em forma de oração interrogativa ("vocês acreditam?"), mas se encontra no início do texto, em forma de oração afirmativa, e poderia ser expressa interrogativamente da seguinte forma: "qual a opinião de vocês sobre a situação que descreverei?".

Diante do funcionamento das mensagens observadas dessa fase, o evento disparador deve ser considerado como o resultado de uma reflexão acerca de determinado aspecto ou situação do processo de ensino e/ou aprendizagem de LE que se deseja compartilhar com os participantes de uma comunidade de investigação. Como mencionamos, essa reflexão pode ser expressa por meio de uma afirmação, questão explícita ou implícita. No primeiro caso, o participante que inicia a discussão pode até mesmo já se encontrar em uma fase de "resolução" sobre o tema (destacamos, nessa situação, que ele pode ter tecido reflexões sobre o tema previamente à elaboração do texto, as quais não são explicitadas na mensagem) e compartilha o resultado de suas análises com o grupo, como podemos observar, por exemplo, na mensagem de Lara:

LARA (25/03): (Tema: Didática) Pode-se afirmar que o bom professor, além de deter sua bagagem de conhecimento, deve ter um bom desempenho de metodologia em sala de aula, ou seja, saber passar para sua turma, de maneira clara, sucinta, e informativa. Nessa questão discute-se, por exemplo, a relação professor-aluno, o bom humor cotidiano do docente, sua disponibilidade, competência, ajuda e, consequentemente, o nível de incentivo que ele exprime. Em prática de língua estrangeira esta reflexão se torna ainda mais complexa, „ter um jogo de cintura pedagógica“" para „não deixar o aluno boiando", e ao mesmo tempo semear o conhecimento e manter um bom relacionamento pessoal e acadêmico.

Na mensagem de Lara e nos elementos discursivos utilizados por ela ("pode-se afirmar que [...]"; "o professor deve ter [...]"; "deve saber [...]"; etc.) notamos que a participante não exprime qualquer dúvida ou curiosidade sobre o tema implícito no tópico "o que é ser um bom professor?". Ao contrário, ela está certa de algo (no caso, da importância da boa didática do professor), porém deseja compartilhar sua certeza e sua reflexão com os participantes do grupo. Assim, sua mensagem atua como evento disparador de uma discussão que irá levar outros participantes 
a refletir sobre o tema abordado, que poderão inclusive colocar em questão a certeza da colega. Nesse aspecto divergimos de Garrison e colaboradores, que atribuem ao evento disparador do processo de desenvolvimento do pensamento crítico como essencialmente um estado de dúvida ou curiosidade.

Diante de ocorrências observadas em nossos dados, concluímos que na fase evento disparador toda mensagem tem o objetivo comum de iniciar uma discussão e trazer uma questão, uma dúvida, bem como um relato de uma experiência curiosa ou intrigante, uma situação, uma certeza ou um insight que se deseje compartilhar com outros participantes e que seja capaz de motivar a reflexão nos integrantes da comunidade. Elas irão apenas se distinguir em sua forma de apresentação (questão implícita, explícita ou relato).

Sintetizamos, a seguir, os elementos discursivos que consideramos marcar essa fase:

a) Nos relatos de experiência, descrição de uma situação: encontramos aqui elementos da metafunção ideacional, uma vez que ocorre a representação de uma realidade e da experiência com o mundo exterior, buscando construir sentidos por meio dos enunciados. Essa representação é realizada por meio de processos materiais da metafunção ideacional (MID) (ex.: alguém/alguma coisa fez, levou, leu, pegou, vai, etc.), existenciais (ex.: alguém/alguma coisa é, tem; existe, há), mentais de percepção (ex.: alguém vê/viu/ouve/ouviu) ou verbais (ex.: alguém disse, falou, etc.). O participante irá se colocar, ou colocar pessoas, como atores dos processos. Em relação às funções do discurso e à metafunção interpessoal (MINT), há a ocorrência de movimento de abrir e iniciar uma discussão, por meio das funções de dar uma informação ou de relatar um fato.

b) Na opinião sobre uma situação exposta: o posicionamento pessoal em relação ao tema ocorre, sobretudo, por meio de processos mentais (ex.: eu acho, penso, considero, posso dizer que, etc.), associados a existenciais ou materiais, característicos da metafunção ideacional. Nota-se também a presença de alguns elementos de valoração, particular da metafunção interpessoal: predominância de julgamento da situação descrita, de modulação e modalização (ex.: acho importante, bom, ruim, etc.). Com relação às funções do discurso, tem-se um movimento de dar opinião.

c) Na elaboração de uma questão: quando há ocorrência de formulação de questões, esta se dá por meio de orações interrogativas e por um processo de pedir informação, opinião, ou validação de uma proposição. A questão pode ser formulada de forma aberta (uso de pronomes interrogativos como quem, quando, qual, etc.) ou fechada (restringe o tipo de resposta. Ex.: isso ou aquilo?). Conforme mencionamos, nota-se que a maioria das mensagens de nossas análises inclui um relato, ou uma contextualização e ao menos uma questão explícita. 
Finalizamos ressaltando que o evento disparador pode ser criado por qualquer membro da comunidade de investigação e poderá levar os participantes a uma fase de elaboração ou de resolução.

\section{Fase de elaboração}

A fase que propomos como elaboração é, em certo sentido, uma associação das fases de exploração com a de integração do modelo de Investigação Crítica (GARRISON; ANDERSON; ARCHER, 2000; GARRISON; ANDERSON, 2003).

Ela é caracterizada pela busca do entendimento da natureza de uma situaçãoproblema, por explicações ou informações relevantes sobre ela, por sugestões de consideração, pela solicitação ou apresentação de narrativas e relatos de experiências pessoais que possam ilustrar, apoiar e/ou divergir da mensagem do evento disparador. Ela tem caráter de respostas ou comentários sobre a informação fornecida no ED, de ideias, ou de integração de outras fontes de informações como textos ou artigos à discussão iniciada. Essa fase pode incluir divergências e/ou convergências entre membros do grupo ou em relação a uma mensagem específica, buscando oferecer apoio ou ideias contraditórias.

A fase de elaboração é marcada pela exploração social de ideias, por um brainstorming sobre o tema, na tentativa de produzir sentidos sobre o que pode parecer confuso, complexo, duvidoso, a partir de elementos como o pensamento criativo (GARRISON, 1991), o ceticismo reflexivo (McPECK, 1981; BROOKFIELD, 1987), a conexão de ideias. Nela pode ocorrer também o insight (McPECK, 1981; GARRISON; ANDERSON, 2003), a percepção de uma possível solução ou hipótese, porém ainda sem certezas, ou seja, os elementos se apresentam ainda sem marcas de posicionamento seguro acerca da proposta. Nessa fase são sinalizadas algumas soluções em processo de elaboração, as quais podem estar em concordância ou discordância com membros do grupo. Enfatizamos que o ponto central que diferencia as soluções propostas nesta fase daquelas da resolução é a ausência de certeza.

É uma fase altamente reflexiva. Os participantes estão intimamente engajados em um discurso crítico, voltado para a compreensão e a conexão de ideias capazes de promover e produzir sentidos, e podem oferecer soluções potenciais. Inclui integração de informação, expressões de convergência e/ou divergência ou a construção de ideias com base nas reflexões dos participantes, por meio da racionalização e/ou justificação. Os participantes discutem a aplicabilidade de determinadas ideias e disso muitas vezes decorrem novas questões.

Os marcadores discursivos característicos desta fase são: 
a) Na convergência com membros do grupo ou mensagem: A convergência com membros do grupo ou mesmo com uma única mensagem é realizada por meio de processos da metafunção ideacional, em especial pelo processo mental cognitivo (concordo; eu também penso assim/acho...; você tem razão..., etc.). Considerando as funções do discurso, os movimentos utilizados são de reagir, apoiar e corresponder à proposição do grupo e/ou de uma mensagem anterior e concordar com ela. Verifica-se a presença de elementos da metafunção interpessoal, como as expressões de valoração: de julgamento, apreciação e/ou afetividade.

BETH (26/03): (Tema: Pronúncia e leitura). Concordo, Ma. (MID: ${ }^{8}$ processo mental; FD: concordar). Realmente, em uma classe com 40 alunos, fica difícil. Mas o que eu acho mais interessante é a leitura em voz alta e a repetição das palavras mais difíceis.

b) Na divergência com membros do grupo ou mensagem: A divergência com membros do grupo ou com uma única mensagem é realizada por meio de processos da metafunção ideacional, em especial pelo processo mental cognitivo (não concordo, não acho, etc.). Considerando as funções do discurso, os movimentos utilizados são de reagir, confrontando a proposição do grupo e/ ou de uma mensagem e respondendo adversamente a ela. Verifica-se a presença de elementos da metafunção interpessoal e marcadores de polaridade negativa (não, nunca, etc.).

ALINE (25/03) (Tema: Interação em sala de aula Ma, já isso eu não concordo muito... (MID: processo mental; FD: confrontar-polaridade negativa) Se a formação de grupos for uma opção do professor, acho legal as pessoas se juntarem com seus „afins“" Nao acho (MID: processo mental; MINT: polaridade negativa) legal essa imposição do professor, principalmente entre alunos crianças, pois eles se sentem intimidados diante de alunos com quem não se dão muito bem.

c) Na conexão de ideias (integrando experiência pessoal, fontes-texto, brainstorming, sugestões de consideração, troca de informação, etc.): a conexão de ideias é realizada pela metafunção ideacional, por meio de processos materiais e existenciais (em relatos, no tempo passado) e pela metafunção interpessoal, fornecendo informações. Sob a perspectiva das funções do discurso, a conexão de ideias é realizada por movimentos de reagir a uma proposição, apoiando, desenvolvendo, elaborando e estendendo as ideias apresentadas. Neste sentido, o participante faz movimentos de clarear a proposição anterior por meio de exemplos (elaborar) ou de estender, dando qualificações de cunho temporal, causal, condicional, etc., e introduzindo

Nos excertos dos dados apresentados utilizaremos as seguintes siglas: MID=Metafunção Ideacional, seguida do tipo de processo, MINT=Metafunção Interpessoal, seguida das relações de modalidade e FD=Função do Discurso. 
novos pontos a serem considerados. As sugestões de considerações envolvem também processos mentais cognitivos e materiais da metafunção ideacional. Nota-se também a presença de elementos de valoração, buscando apoiar ou divergir da argumentação. Além disso, verifica-se que é possível a ocorrência de elaboração de novas questões que irão atuar como impulso para novos movimentos de desenvolver e elaborar.

Exemplos de mensagens caracterizadas como da fase de elaboração:

ALINE (3/06) (Tema: False friends). Verdade Lu, (MID: processo mental; FD: apoiar) as duas palavras juntas acabam confundindo mesmo... lembrei daquela história (FD: desenvolver e estender uma ideia) do "like" e do "as", se não tivessem sido discutidas juntas, nao teriamos feito tanta confusão.

Aline concorda com Lu e estende sua argumentação ilustrando seu posicionamento com a lembrança de uma experiência comum na sala de aula de língua inglesa na universidade, quando lhes foram apresentadas duas estruturas gramaticais similares simultaneamente.

MAÍRA (01/04) (Tema: Decorar ou não?) Gente, quando eu estava no colégio, minha professora de inglês pedia pra gente traduzir um livro por bimestre. Eram livros bem pequenininhos com um tema único, então fixávamos o vocabulário referente aquele tema. E posso dizer que isso funcionava bem. Conforme fomo ficando mais velhos, a gente não precisava mais traduzir, mas tínhamos de ler o livro, para fazer uma prova sobre ele. Aí passamos a ler livros maiores, lembro-me até que lemos uma adaptação do Drácula. Deu muito certo, pelo menos com a minha turma. $O$ fato de estarmos traduzindo, e precisarmos olhar no dicionário várias vezes, nos ajudava a fixar a palavra. Mas percebam que este é um trabalho a longo prazo, ne? Não adianta querer trabalhar com isso um ano para o aluno prestar vestibular...(FD: desenvolver, estender a ideia)

Maíra desenvolve o raciocínio apresentado no tópico por colegas relatando uma experiência pessoal durante o seu processo de aprendizagem de inglês na fase escolar.

d) Na sinalização de soluções: Nessa fase os participantes podem iniciar a busca por soluções, porém ainda sem expressar segurança sobre elas. Esse processo é realizado por meio de processos mentais cognitivos (metafunção ideacional). É possível que haja a ocorrência de elementos de valoração positiva e/ou negativa de julgamento e apreciação (modalidade: metafunção interpessoal), porém ainda com baixo ou médio compromisso modal.

Exemplo de mensagem dessa fase com destaque para os elementos que a caracterizam: 
MAIRA (29/04): (Tema: A inclusão que exclui?). Alinezinha, talvez (MINT: modalização: baixa frequência) a ideia do monitor funcione bem no que diz respeito ao aprendizado das crianças, mas realmente você tem razão no que colocou. Este acompanhamento na sala de aula, durante os exercicios, provome uma especie de "segregação"... Aí eu acho que se perde um pouco a ideia da inclusão não é? Pra que trazer o aluno especial para a escola, se ele fica excluído dentro da instituição? Talvez_o ideal (MINT: modalização: baixa frequência), fosse fazer aulas especiais com esses alunos, no horário oposto ao da grade normal. Assim eles iriam aprendendo as coisas no seu ritmo e seguiam acompanhando as aulas normais. Acho que isso pode surtir efeito. Ainda não li o texto que a Cintia indicou, mas o farei com certeza. Este assunto merece muita atenção mesmo...

Maria concorda com Aline e sinaliza uma solução para a situação da inclusão de alunos especiais, porém nota-se ainda uma incerteza em sua argumentação, marcada, sobretudo, pelo elemento de baixa frequência de modalização (talvez) e pela ausência de elementos de julgamento com alto grau de compromisso modal.

\section{Fase de resolução}

Essa fase corresponde à expressão de possibilidade de implementação de uma ideia determinada e de aplicabilidade de uma proposta, por meio de um maior grau de certeza e segurança.

A resolução de um problema ocorre pela construção de um quadro significativo ou pela apresentação de uma solução contextual significativa (GARRISON; ANDERSON, 2003). Ela acessa criticamente a viabilidade da solução proposta por meio de aplicação direta ou hipotética. A resolução requer um compromisso para testar a solução dedutivamente, talvez por meio de uma implementação indireta ou experimento do pensamento. Em contextos não educacionais isso significa implementar uma solução ou testar hipóteses. Todavia, nos educacionais, a aplicação prática das sugestões durante o período em que ocorrem as discussões nem sempre é possível. Ela geralmente ocasiona, assim, um teste indireto usando experimentos mentais e construindo consensos na comunidade. (GARRISON; ANDERSON; ARCHER, 2001).

Podemos nos questionar se esse fato não ocorre também na fase de elaboração. Desse modo, reiteramos que a fase de resolução difere da elaboração no sentido de que as opiniões acerca de possíveis soluções são apresentadas com maior grau de segurança e certeza: o participante demonstra maior propriedade e segurança em sua opinião e esta geralmente é acompanhada de justificativas bem fundamentadas.

Os marcadores discursivos característicos desta fase são: 
a) Na aplicação ao mundo real: são descritas experiências vividas ou hipotéticas, por meio de processos materiais, existenciais e expressões de alto grau de valoração (julgamento e apreciação. Ex.: é excelente, muito importante, etc.). Pode haver a expressão explícita de intenção de aplicação futura no mundo real e/ou de convergência com uma ideia proposta. A aplicação ao mundo real está frequentemente associada à defesa de soluções, como observaremos mais adiante nos exemplos.

b) Para defender soluções: as soluções apresentadas podem estar em convergência com o grupo ou uma mensagem (FD: concordar) ou divergência (discordar) ou ser proposta sem referência explícita a outras mensagens.

Os elementos principais de distinção dessa fase da elaboração são, portanto, a amplificação (maior.../mais... que, por exemplo), alta modalização de frequência e probabilidade (é certo, com certeza, sem dúvida, sempre, etc.) e a modulação (alto grau de obrigação e inclinação, como ter que, deve, precisa, é fundamental/essencial que, etc.).

Exemplo de mensagem que defende soluções, ao mesmo tempo em que advogam determinada aplicação ao mundo real:

PATRICIA (07/06): (Tema: A inclusão que exclui?). Acredito que a forma como se dá essa inclusão é que precisa (MINT: modulação: obrigação) sofrer retificações. Como são alunos com necessidades especiais, sem dúvida (MINT: modalização: alto grau de probabilidade) que precisam de (MINT: modulação: obrigação) uma atenção maior por parte dos professores. E para isso, este tipo de classe (que recebe um aluno especial) deve ter (MINT: modulação: obrigação) um número reduzido de alunos e número suficiente de monitores que auxiliem o professor no ensino/aprendizagem.

c) Para adicionar informações complementares: para defender soluções, é feito também o movimento de reagir, apoiando e desenvolvendo uma proposição, por meio de elementos de alto grau de valoração e/ou modulação.

ANA MARIA (26/05): (Tema: A inclusão que exclui?). Realmente Lu... (MINT: processo mental; FD: apoiar) é uma questão complicada e delicada.... o que acaba acontecendo é uma exclusão dentro da inclusão.... o que falta nas escolas, (MINT: alto grau de valoração/ julgamento) já que querem manter essa "inclusão", é (MID: processo existencial) uma organização maior e uma atenção maior_(MINT: alto grau de valoração) a esses alunos...

MAÍRA (26/03): (Tema: Decorar ou não?). Eu concordo com a Lea que só há (MID: processo existencial) duas maneiras de se ampliar vocabulários: ou vivenciando a língua ou decorando. Mas realmente (MINT: alto grau de modalização: probabilidade) eu não acredito neste método da 
decoreba, porque nem tudo se fixa na nossa cabeça. Acho que uma boa alternativa é trazer o idioma pra mais perto do aluno, buscando proporcinar alguma vivência pra ele. Um artíficio interessante (MINT: médio grau de valoração) é ministrar as aulas no idioma, sem falar português. Isso ajuda muito (MINT: médio grau de valoração), pelo menos pra mim ajuda, pois você ouve a mesma palavra várias vezes, e vai compreendendo seu significado pelo contexto.

Sobre as fases de elaboração e resolução, é importante salientar ainda que existem casos de mensagens que se inserem em um espaço de interseção de ambas, ou seja, mensagens que possuem características da fase de elaboração, porém já apresentam algumas soluções bastante evidentes para o problema ou para a reflexão inicial proposta. Por exemplo:

NEIDE (26/05): (Tema: Situações desagradáveis) É uma situação realmente constrangedora, mas penso (MID: processo mental) que se o professor se impor, a situação realmente (MINT: alto grau de modalização: probabilidade) mudaria, mas não se impor de uma forma autoritaria mas sim de uma forma com que os alunos passem a respeitalo e com uma certa interação aluno-professor com certeza (MINT: alto grau de modalização: probabilidade) todo o clima da aula irá mudar, e se não resolver talvez (MINT: baixo grau de modalização: probabilidade) chamar a diretora ou pais.

Neide concorda com os participantes desse tópico sobre a ousadia dos alunos e desrespeito ao professor em uma situação ocorrida em uma escola pública, quando um aluno arremessa um tênis em direção à lousa. Ela manifesta sua opinião sobre o fato por meio de um processo mental e apresenta ainda possíveis soluções, as quais são representadas primeiramente por meio de expressão com alto grau de valoração (com certeza) e em outra com baixo (talvez), ou seja, sem grande segurança. Consideramos que as mensagens de Neide podem ser um exemplo que se enquadra entre a fase de elaboração e a de resolução, pois contêm elementos importantes de ambas.

As reflexões que apresentamos baseiam-se nas últimas análises (análises 3a e 3b) do corpus e tiveram como referência o modelo proposto para esta investigação. ${ }^{9}$ Como mencionamos, notamos uma maior facilidade para a categorização das mensagens em fases e um alto grau de coerência nas classificações realizadas nas duas diferentes análises.

Destacamos ainda um aspecto que se tornou mais claro durante a última etapa de análise. Chamou-nos a atenção o fato de que os estudantes, na maioria das mensagens, não se reportam a estudos teóricos para embasar suas opiniões.

9 Confira Figura 4. 
Mesmo observando que algumas argumentações são desencadeadas por discussões teóricas prévias, realizadas em sala de aula, a referência teórica não é indicada, como por exemplo na mensagem a seguir:

\begin{abstract}
ALINE (03/06): (Tema: Jogos em sala de aula). Aproveitando a ultima exposicao feita na aula de Prática de LE, que falou sobre os jogos competitivos e cooperativos em sala de aula, resolvi fazer a experiencia com os meus aluninhos da sexta série. Só que é aula de Português, nao de Ingles, não sei se ajudará muito nas nossas discussões sobre LE.Em nossa última aula avisei que na próxima faríamos um jogo em que todos deveriam se ajudar para cumprir as tarefas e que a cada tarefa cumprida pela equipe todos receberiam um brinde. Resolvi fazer isso pois das outras vezes que fiz jogos competitivos para dar o conteúdo e eles ficavam mais preocupados em fazer pontos do que em aprender. A aula será na próxima terça-feira e espero na quarta já poder contar o resultado para voces.
\end{abstract}

Aline, assim como a grande parte dos participantes, não faz referências específicas ao texto discutido presencialmente para dar suporte à sua reflexão. Apesar de ela se reportar ao texto discutido em aula, ela respalda sua proposta prioritariamente em experiências, crenças e conhecimentos interiorizados.

Alguns alunos fazem indicações de sites, também o professor o faz, mas observa-se que a argumentação nas mensagens poderia ter sido mais fortemente embasada com referências à teoria. Nessa perspectiva, destacamos o papel do professor para influenciar tal processo. Notamos que este, muitas vezes, poderia/ deveria contribuir mais com indicações de leituras e referências aos licenciandos na direção de incentivar os futuros professores a "refletir com bases científicas".

Tendo descrito o modelo proposto e os dados da pesquisa, passaremos no próximo item para as nossas considerações finais

\title{
Considerações finais
}

Este trabalho teve como objetivo apresentar uma pesquisa que investigou o uso de fóruns online no desenvolvimento do pensamento crítico na formação inicial de professores de LE, mais especificamente durante os estágios supervisionados. Foi constituído um ambiente virtual para a disciplina Estágio Supervisionado e Prática de Ensino de LE (alemão e inglês) e utilizadas diferentes ferramentas ao longo da disciplina. O recorte de nossa análise centrou-se em três fóruns online.

A principal razão para propor a utilização desses três fóruns online durante os estágios supervisionados foi promover a reflexão, a troca de experiência, a construção de conhecimento, a partir das discussões em fóruns sobre a prática 
dos licenciandos, buscando assim impulsionar a manifestação do pensamento crítico acerca de situações de sala de aula e a formação crítico-reflexiva dos professores. Outra preocupação foi propiciar a experiência do uso de ferramentas computacionais para fins educacionais e expor os participantes da pesquisa às tecnologias de comunicação, não para entretenimento, mas para a construção de conhecimento durante a formação inicial.

Os resultados nos levaram a afirmar que o uso de fóruns online é de grande valia para a construção de conhecimento e o desenvolvimento do pensamento crítico dos futuros professores. Tal conclusão se baseou especialmente na triangulação dos dados obtidos por meio da análise das discussões nos fóruns, do seu uso, bem como das avaliações do professor-pesquisador e dos alunos sobre a utilização desse recurso tecnológico.

As características dos fóruns online permitem a comunicação assíncrona, a partir da qual é possível a troca de experiências, o esclarecimento de dúvidas, a reflexão sobre diferentes temas, em tempos e espaços distintos entre os participantes. Para que isso ocorra, é importante que tal comunicação mediada por computador se realize segundo as premissas de uma comunidade de investigação, formada pelas presenças social, de ensino e cognitiva, que irá, assim, favorecer o desenvolvimento do pensamento crítico. Dessa forma, pretende-se contribuir para a formação de professores capazes de lidar com as imprevisibilidades da sala de aula e de realizar análises contextuais coerentes, a fim de poder fundamentar suas ações em seu conhecimento e em suas reflexões acerca de uma situação específica.

Os resultados apontaram ainda para uma abrangência de temas de discussões, que foram muito além do "racionalismo técnico", ao qual se opõem pesquisadores do campo de formação de professores: as discussões favoreceram o processo de reflexão antes, durante e depois da ação, no sentido defendido por Schön e seus seguidores.

Nossas reflexões nos remetem a Leffa (2009), que propõe a sala de aula como sistema aberto e não como uma "redoma de vidro" (em referência metafórica a um sistema fechado). A noção de sala de aula como sistema aberto fica evidente em nossa proposta diante da constatação de que muitas das mensagens eram enviadas pelos alunos nos finais de semana, em horários e dias fora daqueles de aulas, em feriados, e algumas foram postadas até mesmo após o término do período letivo. Dado o caráter de durabilidade da escrita em fóruns online, é possível que os participantes sempre recuperem discussões iniciadas anteriormente, em momentos em que elas parecerem mais pertinentes ou adequadas a eles, permitindo a construção de sentidos e de conhecimento. A ocorrência de tal fato ficou evidenciada nas datas de postagens das mensagens. 
Com base no trabalho com fóruns e em nossas análises, podemos afirmar que o uso da ferramenta durante as práticas iniciais permite a troca de experiências entre os alunos, o trabalho colaborativo, a indicação fácil e rápida pelo professor de material pertinente ao processo de ensino e aprendizagem de LE, o acompanhamento das discussões, a intervenção do professor em situações que considere necessário, a articulação entre teoria-prática e o esclarecimento de dúvidas.

Outro aspecto que merece destaque é a possibilidade oferecida por esse tipo de atividade para o desenvolvimento de habilidades no uso desse recurso tecnológico para fins educacionais, levando os participantes a uma melhor compreensão de sua organização, seus propósitos e a uma maior proficiência no que diz respeito ao gênero fóruns online.

Partindo de modelos e indicadores de análises anteriores, baseados em Garrison, Anderson e Archer (2001), elaboramos uma nova proposta de modelo que permitiu maior flexibilização e clareza para a classificação das mensagens. De acordo com esse modelo, o pensamento crítico se manifesta em três fases nos fóruns: ele se inicia sempre na fase evento disparador, passa então para a elaboração ou para a resolução. As três fases se encontram inseridas em um processo maior de trocas e deslocamentos entre o mundo interior e exterior e são fortemente influenciadas pelas presenças social e de ensino. Essa proposta de modelo difere das anteriores, na medida em que oferece mais elementos para a classificação das mensagens e possui um caráter não linear.

A fase evento disparador dá início à discussão de um tema e é caracterizada pela reflexão acerca de um aspecto inerente ao processo de ensino e aprendizagem de línguas ou pela problematização de um tema nesse campo. A função discursiva geral dessa fase é de abrir um discurso.

A fase elaboração tem como principais características: a convergência e/ou divergência do grupo ou de uma das mensagens, a busca pelo entendimento de uma situação-problema e por explicações ou informações relevantes sobre ela, a sugestão de considerações, o brainstorming, a exploração e conexão de ideias, o ceticismo crítico, os insights, a consideração de uma hipótese e sugestões de solução, porém sem evidências de certeza. Ao contrário, as sugestões de solução aparecem nessa fase marcada por estado de insegurança quanto à proposição. É uma fase altamente reflexiva, com os participantes intimamente engajados na discussão e em seus discursos, argumentando, ponderando, racionalizando, trazendo suas reflexões para o meio virtual e possíveis soluções.

A fase resolução tem como característica principal a apresentação de soluções para uma problemática ou um tema, com propriedade, maior segurança e menor número de sinalização de dúvidas. Nela podem ser apresentados 
relatos de vivências ou de situações hipotéticas, com o intuito de contextualizar, exemplificar e/ou justificar a proposta. É uma fase em que se busca a aplicação de ideias no mundo real, adicionando-se informações complementares e defendendo propostas. O grande diferencial dessa fase, em relação à fase de elaboração, é a maior segurança na apresentação de possíveis soluções. As fases elaboração e resolução podem estar também em interseção, ou seja, pode-se encontrar, por vezes, uma (inter)fase caracterizada pela combinação das duas mencionadas.

À guisa de conclusão, enfatizamos que, diante das dificuldades encontradas por diversos docentes para a supervisão dos estágios obrigatórios, o ambiente virtual e, em especial, os fóruns, demonstraram ser ferramentas valiosas, que deveriam/poderiam ser mais utilizados, pois possibilitam contemplar vários objetivos previstos na legislação da área, como a necessidade de promover reflexão, a articulação teoria-prática, e o enriquecimento do processo de formação com tecnologias digitais, além de contribuir para uma formação docente coerente com a sociedade de informação atual.

Como professores formadores, é fundamental que estejamos atentos às novas ofertas, demandas, oportunidades, possibilidades, aos novos desafios e que estejamos sempre buscando o aprimoramento dos profissionais da educação que estamos formando.

ROZENFELD, C. O. de F. Online forums in critical and reflective training of foreign language teachers: a critical thinking representation in phases in/by language. Alfa, São Paulo, v.58, n.1, p.35-62, 2014.

- ABSTRACT: This paper describes an investigation into the initial training of foreign language teachers (German and English) and the internships required in the fourth year, considering the possibility that online forums may provide a virtual environment for the manifestation of critical thinking by future teachers. We analyze the messages and themes addressed in three forums, based on concepts of critical thinking and on the theoretical model of Practical Inquiry proposed by Garrison, Anderson and Archer (2000; 2001). For a better understanding of the phases in discussions on topics, we use the model of these authors, also identifying some discourse markers characterized by them, mainly based on the assumptions of Systemic Functional Linguistics (HALLIDAY, 1994) and on the types of conversational moves proposed by Eggins and Slade (1997). A new model was created based on the selected theoretical underpinnings and on the analysis of the data, as well as the conclusion was that online forums can be considered an important tool for the manifestation of teachers' critical thinking and for a critical reflexive education, in a context marked by the specificities of information society.

- KEYWORDS: Online Forums. Critical Thinking. Supervised Foreign Language Internship. Initial Teachers Training. 


\section{REFERÊNCIAS}

BROOKFIELD, S. D. Developing critical thinkers. San Francisco: Jossey-Bass, 1987. CONSELHO NACIONAL DE EDUCAÇÃO. Institui Diretrizes Curriculares Nacionais para a Formação de Professores da Educação Básica, em nível superior, curso de licenciatura, de graduação plena. Resolução CNE/CP 1/2002. Diário Oficial da União: República Federativa do Brasil, Brasília, DF, 9 abr. 2002. Disponível em: $<$ http://portal.mec.gov.br/cne/arquivos/pdf/CP012002.pdf>. Acesso em: 11 set. 2012.

DEWEY, J. Como pensamos. São Paulo: Companhia Ed. Nacional, 1959a.

Vida e educação. São Paulo: Companhia Ed. Nacional, 1959b.

EGGINS, S.; SLADE, D. Analysing casual conversation. London: Continuum, 1997.

FREIRE, P. Educação e mudança. São Paulo: Paz e Terra, 1979.

GARRISON, R. Critical thinking in adult education: a conceptual model for developing critical thinking in adult learners. International Journal of Lifelong Education, Lewes, v.10, n.4, p. 287-303, 1991.

GARRISON, R.; ANDERSON, T. E-Learning in the 21st Century: a framework for Research and Practice. London: Routledge Falmer, 2003.

GARRISON, R.; ARCHER, W. A transactional perspective on teaching and learning: a framework for adult and higher education. Oxford: Pergamon, 2000.

GARRISON, R.; ANDERSON,T.; ARCHER,W. Critical thinking, cognitive presence and computer conferencing in distance education. American Journal of Distance education, Pennsylvania, v.15, n.1, p.7-23, 2001.

. Critical inquiry in a text-based environment: computer conferencing in higher education. Internet and Higher Education, Stanford, v.2, n.2-3, p.1-14, 2000.

GERVAI, S. M. S. A mediação pedagógica em contextos de aprendizagem online. 2007. 249f. Tese (Doutorado em Linguística Aplicada e Estudos da Linguagem) Pontifícia Universidade Católica de São Paulo, São Paulo, 2007.

HALLIDAY, M. A. K. An introduction to Functional Grammar. London:Arnold, 1994.

LEFFA, V. J. Se mudo o mundo muda: ensino de línguas sob a perspectiva do emergentismo. Calidoscópio, São Leopoldo, v.7, n.1, p.24-29, jan./abr. 2009.

McPECK, J. E. Critical Thinking and Education. Oxford: Martin Robertson, 1981.

MOITA LOPES, L. P. Oficina de Linguística Aplicada. Campinas: Mercado de Letras, 1996. 
NEVES, M. H. de M. A Gramática: história, teoria e análise, ensino. São Paulo: Ed. da UNESP, 2002.

NÓVOA, A. Vidas de professores. Porto: Porto Ed., 1992.

PERRENOUD, P. A prática reflexiva no ofício do professor: profissionalização e razão pedagógica. Porto Alegre: ARTMED, 2002.

PIMENTA, S. G. Professor reflexivo: construindo uma crítica. In: PIMENTA, S. G.; GHEDIN, E. (Org.). Professor Reflexivo no Brasil: gênese e crítica de um conceito. São Paulo: Cortez, 2002. p.17-52.

ROZENFELD, C. C. F. O uso de fóruns online na formação inicial de professores de língua estrangeira: análise da manifestação do pensamento crítico na/pela linguagem. 2011. 212f. Tese (Doutorado em Linguística e Língua Portuguesa) Faculdade de Ciências e Letras, Universidade Estadual Paulista, Araraquara, 2011.

SCHÖN, D. A. Educating the Reflective Practioner. San Francisco: Jossey-Bass Publishers, 1987.

. The Reflective Practioner: how professionals think in action. Inglaterra: Basic Books, 1983.

THOMPSON, G. Introducing functional Grammar. London: Arnold; New York: Oxford University Press, 2004.

VIEIRA-ABRAHÃO, M. H. A prática de sala de aula, a formação e o desenvolvimento do professor de línguas. In: MACIEL, R. F.; ARAUJO, V. A. (Org.). Ensino de Língua Inglesa: contribuições da Lingüística Aplicada. 11.ed. Campo Grande: Ed. da UNAES, 2007. v.1, p.17-42.

ZEICHNER, K. M.; LISTON, D. P. Reflective Teaching: an introduction. Mahwah: Lawrence Erlbaum Associates Publishers, 1996.

Recebido em novembro de 2012.

Aprovado em abril de 2013. 